\title{
First report of Panstrongylus megistus (Hemiptera, Reduviidae, Triatominae) in the State of Acre and Rondônia, Amazon, Brazil
}

\author{
Mariane Albuquerque Lima Ribeiro Castro ${ }^{\mathrm{a}, \mathrm{b}}$, Gabriela Vieira de Souza Castro ${ }^{\mathrm{a}, \mathrm{b}}$, \\ Janis Lunier de Souza ${ }^{c}$, Cláudio Rodrigues de Souza ${ }^{c}$, Leandro José Ramos ${ }^{\mathrm{a}}$, Jader de Oliveira ${ }^{\mathrm{d}, \mathrm{e}}$, \\ João Aristeu da Rosa ${ }^{\mathrm{d}, \mathrm{e}}$, Luis Marcelo Aranha Camargo ${ }^{\mathrm{b}, \mathrm{f}, \mathrm{g}, \mathrm{h}}$, \\ Dionatas Ulises de Oliveira Meneguetti ${ }^{\mathrm{b}, \mathrm{i}, \mathrm{j}, *}$
}

a Center for Health Sciences and Sports, Federal University of Acre, Rio Branco, Acre, Brazil

${ }^{\mathrm{b}}$ Stricto Sensu Graduate Program in Health Science in Western Amazon, Federal University of Acre, Rio Branco, Acre, Brazil

${ }^{\mathrm{c}}$ Department of Entomology of the State Department of Health, Rio Branco, Acre, Brazil

d Department of Biological Sciences, Faculty of Pharmaceutical Sciences, State University of São Paulo Júlio of Mesquita Filho, Araraquara, São Paulo, Brazil

e Stricto Sensu Graduate Program in Biosciences and Biotechnology, State University of São Paulo Júlio of Mesquita Filho, Araraquara, São Paulo, Brazil

${ }^{\mathrm{f}}$ Institute of Biomedical Sciences-5, University of São Paulo, Monte Negro, Rondônia, Brazil

${ }^{\mathrm{g}}$ Department of Medicine, University Center São Lucas, Porto Velho, Rondônia, Brazil

${ }^{\text {h }}$ Center for Research in Tropical Medicine, Porto Velho, Rondônia, Brazil

${ }^{\mathrm{i}}$ Stricto Sensu Postgraduate Program in Science, Innovation and Technology for the Amazon, Federal University of Acre, Rio Branco, Acre, Brazil

${ }^{\mathrm{j}}$ College of Application, Federal University of Acre, Rio Branco, Acre, Brazil

\section{A R T I C L E I N F O}

\section{Keywords:}

Triatominae

Chagas disease

Amazon

\begin{abstract}
A B S T R A C T
Introduction: This article reports, for the first time, the occurrence of Panstrongylus megistus in the Brazilian Western Amazon.

Methods: Specimens of P. megistus were collected in the cities of Rio Branco, Acre and Extrema, Rondônia. Results: The number of triatomine species in the State of Acre increased from eight to nine and in Rondônia from seven to eight. This was also the first report of $P$. megistus in the Brazilian Western Amazon.

Conclusion: The occurrence of $P$. megistus in the Western Amazon evidences an epidemiological alert, since it is an important vector of $T$. cruzi.
\end{abstract}

\section{Introduction}

American Trypanosomiasis or Chagas disease is a neglected tropical disease that affects six to eight million people worldwide and is considered endemic in Mexico, as well as Central and South America, but it has been also spreading in non-endemic countries through the migration of people affected by the disease (Coura and Viñas, 2010).

The vectors of Chagas disease belong to the Reduviidae family and subfamily Triatominae, which contains more than 153 species, grouped into 18 genera, some of which are intimately adapted to human dwellings, which potentiates the vector transmission of Trypanosoma cruzi, the etiological agent of this disease (Mendonça et al., 2016; Souza et al., 2016; Oliveira and Alevi, 2017).

In the Amazon, there are 31 recognized triatomine species grouped into nine genera, and in the Brazilian Amazon, there are at least 22 wild triatomine species belonging to eight described genera, more than 10 related of which are to Trypanosoma cruzi infection (Souza et al., 2016;
Meneguetti et al., 2016).

In the states of Acre and Rondônia, five species of triatomines are described: Rhodnius montenegrensis (Rosa et al., 2012; Meneguetti et al., 2015), Rhodnius robustus (Barata et al., 1988; Massaro et al., 2008), Rhodnius pictipes (Barata et al., 1988; Massaro et al., 2008), Panstrongylus geniculatus (Massaro et al., 2008; Gurgel-Gonçalves et al., 2012) and Eratyrus mucronatus (Meneguetti et al., 2011; Obara et al., 2013), while Rhodnius stali (Meneguetti et al., 2016), Rhodnius neglectus (Ramos et al., 2018a) and Triatoma sordida (Ramos et al., 2018b) are only found in Acre and Rhodnius milesi (Massaro et al., 2008) and Panstrongylus lignarius (Terassini et al., 2017) the state of Rondônia.

The present study reports for the first time the occurrence of the species Panstrongylus megistus in the States of Acre and Rondônia, which is also the first report in the Western Amazon.

\footnotetext{
* Corresponding author at: Universidade Federal do Acre (UFAC), Campus Universitário - BR 364, km 4 - Distrito Industrial, CEP: 69.920 - 900, Rio Branco, Acre, Brazil.

E-mail address: dionatas@icbusp.org (D.U.d.O. Meneguetti).
} 


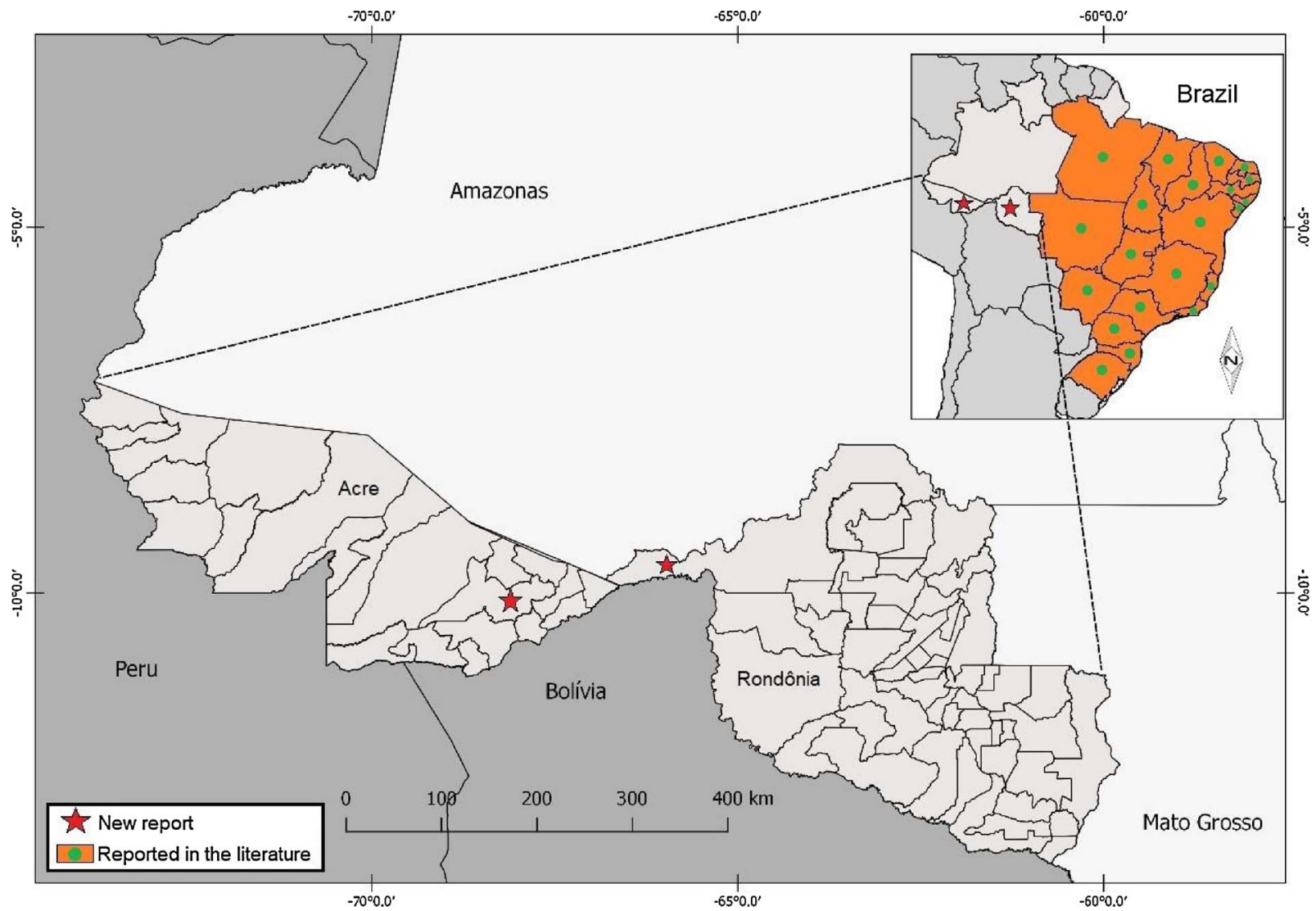

Fig. 1. Distribution of Panstrongylus megistus in Brazilian.

\section{Materials and methods}

Triatomines were found in the municipalities of Rio Branco, Acre ( $9^{\circ} 58^{\prime} 56^{\prime \prime} \mathrm{S}-67^{\circ} 52^{\prime} .41^{\prime \prime} \mathrm{W}$ ) and Porto Velho, Rondônia (Extrema district) $\left(9^{\circ} 46^{\prime} 27^{\prime \prime} \mathrm{S}-66^{\circ} 21^{\prime} .09^{\prime \prime} \mathrm{W}\right)$, Brazil (Fig. 1). In both municipalities the specimens were collected in residences of peri-urban regions, but without evidence of the occurrence of domiciliation. In Rio Branco, the two specimens collected were sent to the Department of Entomology of the Municipal Health Department and then sent to the Laboratory of Tropical Medicine (LABMEDT) of the Federal University of Acre (UFAC). The only specimen collected in Porto Velho (Extrema district), was also referred to LABMEDT of UFAC.

The initial identification of the species occurred in LABMEDT, considering the morphological characteristics described by Lent and Wygodzinsky (1979), and later referred to the Institute of Biological Sciences of the Faculty of Pharmaceutical Sciences, University Paulista Júlio de Mesquita Filho (UNESP), in Araraquara, São Paulo, Brazil, where the species was confirmed. No analysis of trypanosomatid infection was performed, since at the time of delivery the specimens were already completely dehydrated.

\section{Results and discussion}

The three triatomines collected, two in the municipality of Rio Branco Acre and one in Porto Velho (Extrema district), Rondônia, were identified as Panstrongylus megistus.

Panstrongylus megistus (Fig. 2) described for the following Brazilian states: Alagoas, Bahia, Ceará, Federal District, Espírito Santo, Goiás, Maranhão, Minas Gerais, Mato Grosso do Sul, Mato Grosso, Pará, Paraíba, Pernambuco, Piauí, Paraná, Rio de Janeiro, Rio Grande do Norte, Rio Grande do Sul, Sergipe, São Paulo, Santa Catarina and Tocantins (Gurgel-Gonçalves et al., 2012), which together with the states of Acre and Rondônia represent 24 Brazilian states where this species occurs.

Panstrongylus megistus is presently the most important Chagas disease vector in Brazil, due to its wide geographic distribution, high capacity to invade and colonize households, and high levels of $T$. cruzi infection (Gurgel-Gonçalves et al., 2012). Humans, birds, dogs, cats, marsupials, rodents, cattle, goats, pigs, among others, have already been found infected (Carcavallo et al., 1997).

The presence of another species of triatomines in the state of Acre and Rondônia has increased the total number of species from eight to nine in Acre and seven to eight in Rondônia.

The occurrence of Panstrongylus megistus in the Western Amazon calls for an epidemiological alert, since it is an important vector species of $T$. cruzi to humans, due to its anthropophilia, and for being mainly found in surroundings and homes, where it has easy access to shelter and an abundant source of food, thus increasing the possibility of transmission of Chagas disease in the states of Acre and Rondônia.

\section{Ethical considerations}

The specimens were collected with permission from the Brazilian Institute of Environment and Renewable Natural Resources [Instituto Brasileiro do Meio Ambiente e dos Recursos Naturais Renováveis (IBAMA)], permanent license no. 52260-1.

\section{Financial support}

Programa Pesquisa Para o SUS: Gestão Compartilhada em Saúde (PPSUS) 001/2015 and 001/2016 - Fundação de Amparo à Pesquisa do Estado do Acre (FAPAC).

\section{Acknowledgments}

Fundação de Amparo à Pesquisa do Estado do Acre (FAPAC). 


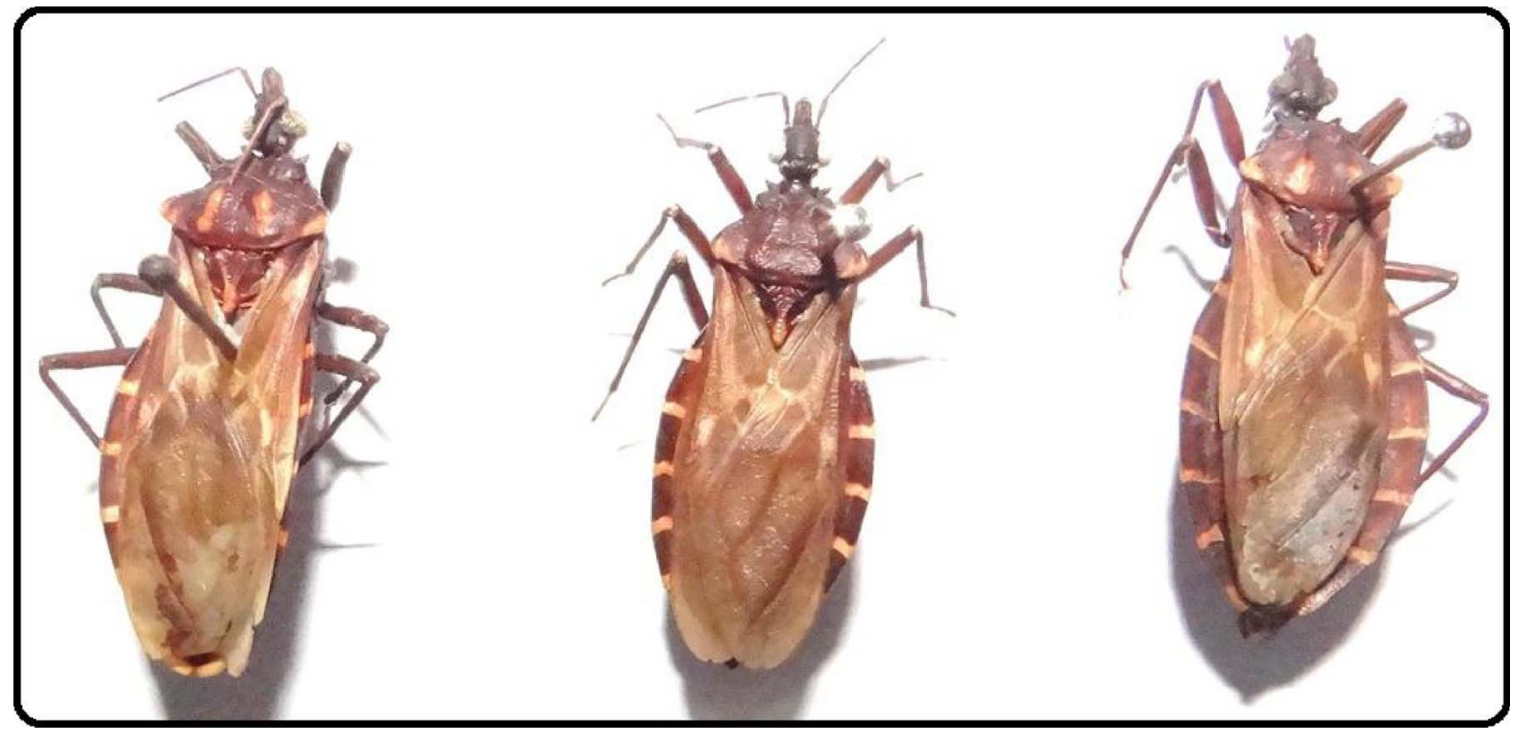

Fig. 2. Dorsal views of Panstrongylus megistus individuals found in the municipality of Rio Branco, State of Acre and Porto Velho, Rondônia (Extrema district), Brazil.

\section{Pró-Reitoria de Pesquisa e Pós-Graduação da Universidade Federal do} Acre (UFAC).

\section{References}

Barata, J.M.S., Rocha, R.M., Rodrigues, V.L.C.C., Ferraz-Filho, A.N., 1988. Primeiro caso autóctone de tripanossomíase americana no Estado do Acre (Brasil) e sua correlação com as cepas isoladas do caso humano e de triatomíneos silvestres da área. Rev. Saude Publica 22, 401-410.

Carcavallo, R.U., Rocha, D.S., Girón, I., Sherlock, I.A., Galvão, C., Martinez, A., et al., 1997. Fontes e padrões alimentares. In: Carcavallo, R.U., Girón, G.I., Juberg, J., Lent, H., organizadores (Eds.), Atlas dos vetores da doença de Chagas nas Américas. Editora Fiocruz, Rio de Janeiro.

Coura, J.R., Viñas, P.A., 2010. Chagas disease: a new worldwide challenge. Nature 465, 56-57.

Gurgel-Gonçalves, R., Galvão, C., Costa, J., Peterson, A.T., 2012. Geographic distribution of Chagas disease vectors in Brazil based on ecological niche modeling. J. Trop. Med. 2012, 1-15.

Lent, H., Wygodzinsky, P., 1979. Revision of the Triatominae (Hemiptera Reduviidae), and their significance as vectors of Chagas' disease. Bull. Am. Mus. Nat. Hist. 163, 123-520.

Massaro, D.C., Rezende, D.S., Camargo, L.M.A., 2008. Estudo da fauna de triatomíneos e da ocorrência de doença de Chagas em Monte Negro, Rondônia, Brasil. Rev. Bras. Epidemiol. 11, 228-240.

Mendonça, V.J., Alevi, C., Pinotti, H., Gurgel-Gonçalves, R., Pita, S., Guerra, A.L., et al., 2016. Revalidation of Triatoma bahiensis Sherlock \& Serafim, 1967 (Hemiptera: Reduviidae) and phylogeny of the T. brasiliensis. Zootaxa 4107, 239-254.

Meneguetti, D.U.O., Trevisan, O., Rosa, R.M., Camargo, L.M.A., 2011. First report of Eratyrus mucronatus, stal, 1859, (Hemiptera, Reduviidae, Triatominae) in the State of Rondônia, Brazil. Rev. Soc. Bra. Med. Trop. 44, 511-512.
Meneguetti, D.U.O., Toja, S.D., Miranda, P.R.M., Rosa, J.Á., Camargo, L.M.A., 2015. First report of Rhodnius montenegrensis (Hemiptera, Reduviidae, Triatominae) in the State of Acre, Brazil. Ver. Soc. Bras. Med. Trop. 48, 471-473.

Meneguetti, D.U.O., Castro, G.V.S., Castro, M.A.L.R., Souza, J.L.S., Oliveira, J., Rosa, J.A., et al., 2016. First report of Rhodnius stali (Hemiptera, Reduviidae, Triatominae) in the State of Acre and in the Brazilian Amazon. Rev. Soc. Bras. Med. Trop. 49, 365-368.

Obara, M.T., Cardoso, A.S., Pinto, M.C.G., Souza, C.R., Silva, R.A., Gurgel-Gonçalves, R., 2013. Eratyrus mucronatus Stål, 1859 (Hemiptera: Reduviidae: Triatominae). First Report in the State of Acre, Brazil, and Updated Geographic Distribution in South America. Check List. 9. pp. 851-854.

Oliveira, J., Alevi, K.C.C., 2017. Taxonomic status of Panstrongylus herreri Wygodzinsky, 1948 and the number of Chagas disease vectors. Brazil. Rev. Soc. Bras. Med. Trop. Lett. 50, 434-435.

Ramos, L.J., Castro, G.V.S., Souza, J.L., Oliveira, J., Rosa, J.A., Camargo, L.M.A., et al., 2018a. First report of Rhodnius neglectus, lent, 1954 (Hemiptera, Reduviidae, Triatominae) in the State of Acre and in the Brazilian western Amazon. Rev. Soc. Bras. Med. Trop. 51 (in press).

Ramos, L.J., Souza, J.L., Souza, C.R., Oliveira, J., Rosa, J.A., Camargo, L.M.A., et al., 2018b. First report of Triatoma sordida, Stål, 1859 (Hemiptera, Reduviidae, Triatominae) in the State of Acre and in the Brazilian western Amazon. Rev. Soc. Bras. Med. Trop. 51 (in press).

Rosa, J.A., Rocha, C.S., Sueli, G., Mara, C.P., Vagner, J.M., Júlio, C.R.F.F., et al., 2012. Description of Rhodnius montenegrensis n. sp. (Hemiptera: Reduviidae: Triatominae) from the state of Rondônia, Brazil. Zootaxa 3478, 62-76.

Souza, E.D., Von Atzingen, N.C., Furtado, M.B., Oliveira, J., Nascimento, J.D., Vendrami, D.P., et al., 2016. Description of Rhodnius marabaensis sp. n. (Hemiptera, Reduviidade, Triatominae) from Pará State, Brazil. Zookeys 62, 45-62.

Terassini, F.A., Stefanello, C., Camargo, L.M.A., Meneguetti, D.U.O., 2017. First report of Panstrongylus lignarius, walker, 1873 (Hemiptera, Reduviidae, Triatominae), in the State of Rondônia, Brazil. Rev. Soc. Bras. Med. Trop. 50, 547-549. 